\title{
A Novel Eye Drop Candidate for Age-Related Macular Degeneration Treatment: Studies on its Pharmacokinetics and Distribution in Rats and Rabbits
}

\author{
Eun-Jeong Choi ${ }^{1}$, Go-Wun Choi ${ }^{1}$, Ju Hee Kim ${ }^{1}$, Hee-Woon Jang ${ }^{1}$, Ju-Hee Lee ${ }^{2} \oplus$, Hyun Ju Bae ${ }^{2}$, \\ Young Gwan Kim ${ }^{2}$, Yong-Bok Lee ${ }^{3}$ (i) and Hea-Young Cho ${ }^{1, *(1)}$ \\ 1 College of Pharmacy, CHA University, 335 Pangyo-ro, Bundang-gu, Seongnam-si, Gyeonggi-do 13488, \\ Korea; choiej5048@gmail.com (E.-J.C.); gwchoi153@gmail.com (G.-W.C.); 20135107@ppharm.org (J.H.K.); \\ heewoon21@gmail.com (H.-W.J.) \\ 2 Kukje Pharma R\&D Center, Sanseong-ro 47, Ansan, Gyeonggi-do 15438, Korea; \\ jhlee@kukjepharm.co.kr (J.-H.L.); hjbae1201@gmail.com (H.J.B.); ykkim@kukjepharm.co.kr (Y.G.K.) \\ 3 College of Pharmacy, Chonnam National University, 77 Yongbong-ro, Buk-Gu, Gwangju 61186, Korea; \\ leeyb@chonnam.ac.kr \\ * Correspondence: hycho@cha.ac.kr; Tel.: +82-31-881-7167; Fax: +82-31-881-7219
}

Received: 3 January 2020; Accepted: 3 February 2020; Published: 4 February 2020

\begin{abstract}
Age-related macular degeneration (AMD) is wearing down of macula of retina, causing a blur or loss of vision in the center of the visual field. It can be categorized into dry or wet AMD. Until now, medical treatments for dry AMD have not been developed yet. The aim of this study was to evaluate pharmacokinetics (PKs) and tissue distribution of CK41016, a novel candidate for dry AMD, after intravenous (IV) or eye drop administration in rats and rabbits. In addition, a simple and sensitive bioanalytical method for CK41016 using ultra performance liquid chromatography-tandem mass spectrometer (UPLC-MS/MS) was developed. PK parameters were estimated by compartmental analysis using a WinNonlin ${ }^{\circledR}$ software version 8.1 (a Certara ${ }^{\mathrm{TM}}$ company). A PK model of CK41016 was well-described by the two-compartment model. The tissue-to-plasma partition coefficient (Kp) of CK41016 was the highest in the vitreous humor of rats and the cornea of rabbits after eye drop administration. In addition, the Caco-2 cell transporter assay confirmed that CK41016 was not an active substrate for the efflux transporter. In summary, the PKs and tissue distribution of CK41016 were successfully evaluated and investigated whether this drug was a substrate of efflux transporters.
\end{abstract}

Keywords: CK41016; dry age-related macular generation; pharmacokinetics; tissue distribution; Caco-2

\section{Introduction}

Age-related macular degeneration (AMD) is one of the causes of adult blindness, due to macular damage of the retina. Symptoms of this disease include distorted vision, blurred vision, a loss in contrast sensitivity, slow recovery of visual function after exposure to bright light, and no vision in the center of the visual field [1].

AMD can be classified into wet AMD and dry AMD. About $10 \%$ of patients with AMD have wet AMD with choroidal neovascularization (CNV), which can cause vision loss. However, the development of laser coagulation, anti-VEGF medication, and photodynamic therapy has reduced the chances of vision loss for patients with wet AMD [2,3]. On the other hand, about $90 \%$ of patients with AMD have dry AMD, which is associated with the formation of drusen, containing lipids, proteins, and undigested cell wastes. Drusen can result from stressors such as oxidative stress caused by 
smoking and aging, and they are located between the retinal pigment epithelium (RPE) and Bruch's membrane [4]. In the late stage of the disease progression, dry AMD can often be a leading step into geographic atrophy (GA) or wet AMD.

Several methods have been studied to treat dry AMD, including physical treatment, cell-based therapy, and drugs. Physical treatments, such as lasers [5-7], implantable telescopic lenses [8,9], and rheopheresis [10,11] have shown no significant benefits in clinical trials. Cell-based therapy $[12,13]$ is the most potent therapy for recovering damaged RPE layers using stem cells. In the case of drugs, a few drug candidates are in the development process, with phase 2 or 3 clinical trials [14-17]. Drugs with the following mechanisms of action are undergoing clinical trials: preventing accumulation of drusen, anti-inflammation, increasing choroidal blood flow, and inhibiting the death of RPE cells influenced by drusen. The administration routes of drugs for dry AMD are mostly oral administration and intraocular injection [18], with a few reports on eye drop formulation [15,19].

CK41016 is a new drug candidate as an eye drop for treating dry AMD. Up to now, there are two reported eye drop formulations of dry AMD drugs in clinical trials, including OT-551 with antioxidant action and MC-1101 increasing blood flow. However, neither of the candidates is appropriate for treating the late stage of dry AMD. On the other hand, CK41016 is suitable for treating late-stage dry AMD, because it can inhibit the death of RPE cells [20].

In the case of topical administrations for dry AMD, it is critical that drugs be delivered to the back of the eye. However, it is hard to reach the back of the eyes through eye drop formulation because of many barriers in the eyes [21]. Therefore, it is necessary to confirm whether a drug is distributed to the back of the eyes or not.

To better understand the pharmacokinetics (PKs) and tissue distribution of CK41016, an efflux transport assay was conducted to investigate its absorption and distribution mechanism. P-glycoprotein (P-gp), breast cancer resistance protein (BCRP), and multidrug resistance protein (MRP) are the three major efflux transporters that affect a drug's absorption and kinetics, drug-drug interactions, and its safety profiles [22]. The efflux transporters, such as P-gp, are expressed in the human RPE [23,24], playing a role in limiting the bioavailability of a drug in the eye [25]. Caco-2 cells that express efflux transporters are usually used as a standard screening tool to investigate the absorption and distribution mechanisms of drug candidates. Therefore, a Caco-2 monolayer cell model was selected for the efflux transport assay.

In this study, PK parameters and tissue distributions of CK41016 were evaluated after IV or eye drop administration in rats and rabbits. In addition, the efflux transport of CK41016 was investigated using Caco- 2 cells.

\section{Results and Discussion}

2.1. Determination of CK41016 Using Ultra Performance Liquid Chromatography-Tandem Mass Spectrometer (UPLC-MS/MS)

In this study, an improved sensitive and selective UPLC-MS/MS method was developed for determining the analyte in biological samples. Chromatographic condition, sample preparation method, and mass spectrometric parameters, such as capillary voltage, collision energy, desolvation temperature, ion source temperature, and flow rates of desolvation and cone gases were optimized to determine CK41016 and the internal standard (amlodipine, IS). Full-scan product mass spectra of CK41016 and IS are shown in Figure 1. Multiple reaction monitoring (MRM) transitions for CK41016 and IS were at $m / z 342.1 \rightarrow 255.1$ and $409.1 \rightarrow 238.1$, respectively. For CK41016, the daughter ion could be detected at $m / z 255.1$ and 144.1. We used $\mathrm{m} / \mathrm{z} 255.1$ for the daughter ion due to its high intensity. Various collision energies were examined to obtain the best abundance of peak. When $20 \mathrm{eV}$ of collision energy was used, the highest sensitivity of CK41016 was obtained. Therefore, $20 \mathrm{eV}$ was chosen as the collision energy for CK41016. 


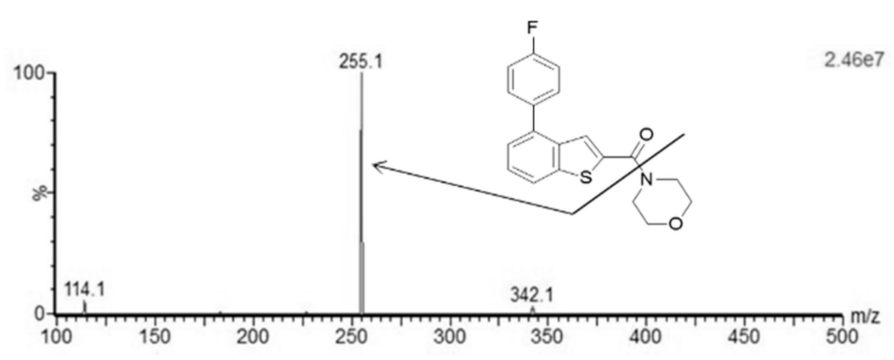

(A)

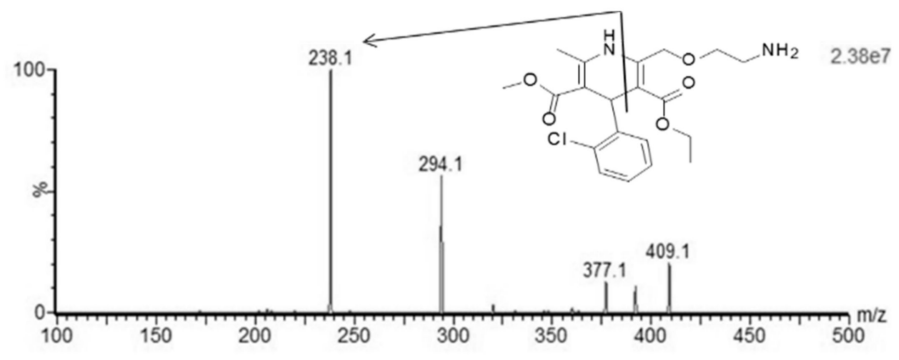

(B)

Figure 1. Positive ion electrospray mass scan spectra of CK41016 (A) and the internal standard (IS) (B).

Considering the selectivity and effects of the coeluting peak for CK41016, we tried various mobile phases, such as water, acidic, and a buffer solution to optimize the liquid chromatography method. When $0.1 \%$ formic acid in water and $0.1 \%$ formic acid in acetonitrile were used, the intensity was higher than in other conditions. In addition, tetrahydrofuran was added to mobile phase A and B to avoid interference with detection of CK41016. To achieve stable base line and better peak shape, we also tested various columns with different sizes and compounds bonded to silica, including HALO $C_{18}$ column (50 mm $\times 2.1 \mathrm{~mm}, 2 \mu \mathrm{m}$ particle size, Advanced Materials Technology, Wilmington, DE, USA); Kinetex $\mathrm{C}_{18}$ column $(50 \mathrm{~mm} \times 2.1 \mathrm{~mm}, 1.7 \mu \mathrm{m}$ particle size, Phenomenex, Torrance, CA, USA); Capcell core $\mathrm{C}_{18}$ column $\left(50 \mathrm{~mm} \times 2.1 \mathrm{~mm}, 2.7 \mu \mathrm{m}\right.$ particle size, Shiseido, Osaka, Japan); Unison UK-C $\mathrm{C}_{18}$ column (50 mm $\times 2.0 \mathrm{~mm}, 3 \mu \mathrm{m}$ particle size, Imtakt Corp., Tokyo, Japan); and Kinetex biphenyl column $(2.1 \mathrm{~mm} \times 50 \mathrm{~mm}, 1.7 \mu \mathrm{m}$ particle size, Phenomenex, Torrance, CA, USA). Kinetex biphenyl column exhibited the best sensitivity, selectivity, symmetric peak shape, and intensity. The retention time was $2.35 \mathrm{~min}$ for CK41016 and $1.18 \mathrm{~min}$ for IS.

For sample preparation, we compared the protein precipitation (PP) method using methanol and acetonitrile and the liquid-liquid extraction (LLE) method using ethyl acetate, ethyl ether, methyl-tert-butyl ether, and methylene chloride to determine the most optimized sample preparation method. PP was not selected due to lower selectivity and recovery than LLE. According to the results of each method, the extraction using methylene chloride was better than other preparation methods in sensitivity, recovery, and intensity at a low concentration. For this reason, a simple LLE method using methylene chloride was adopted for the determination of CK41016.

\subsection{Method Validation Result}

Method validation was conducted according to the FDA Guidance for Industry: Bioanalytical Method Validation [26].

\subsubsection{Selectivity and Specificity}

The representative chromatograms of the blank plasma (A), spiked rat plasma with CK41016 at lower limit of quantification (LLOQ) of $0.1 \mathrm{ng} / \mathrm{mL}$ and the IS $(20 \mathrm{ng} / \mathrm{mL}$ ) in extracted blank plasma (B), standard solution of CK41016 (0.1 ng/mL) and IS (C), and rat plasma taken at $5 \mathrm{~min}$ after eye drop 
administration of $75.21 \mu \mathrm{g} / \mathrm{kg}$ CK41016 (D) are shown in Figure 2. As seen in the figure, the matrix effect in plasma and tissues of rats and rabbits did not exceed $15 \%$, and no significant chromatographic interferences were observed with CK41016 and the IS at their retention times in drug-free plasma and tissues.

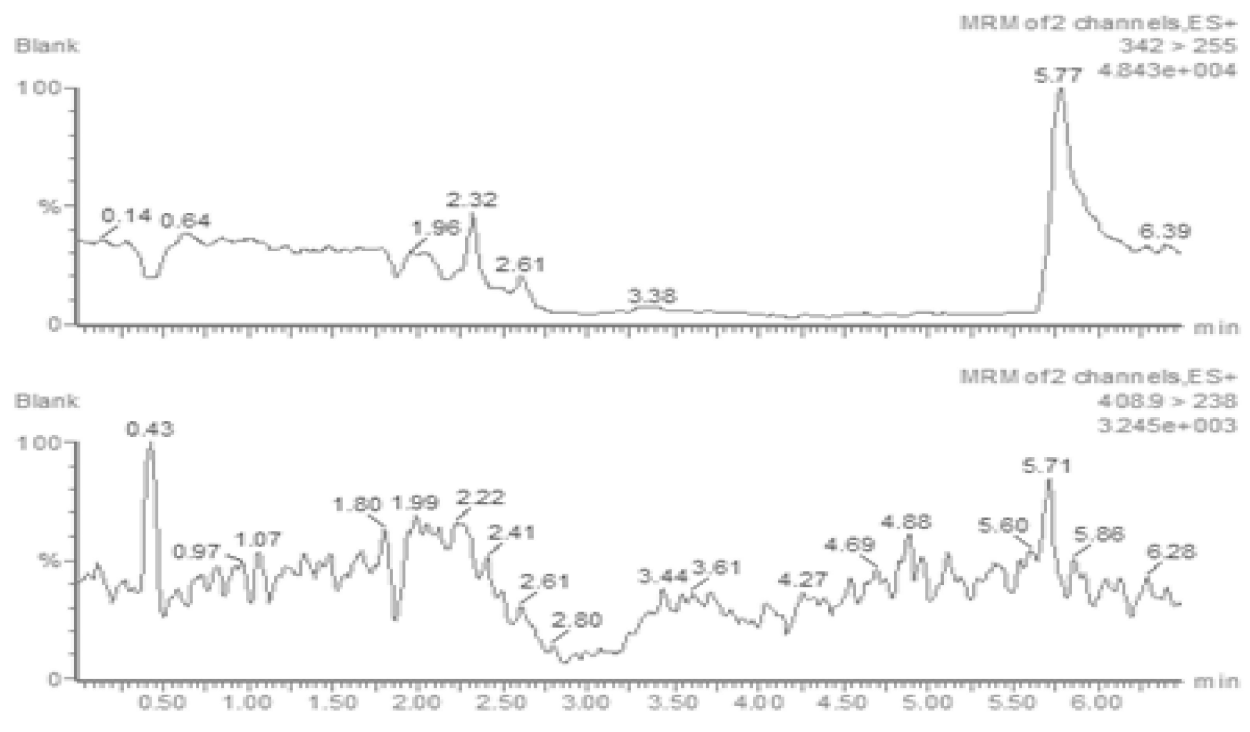

(A)

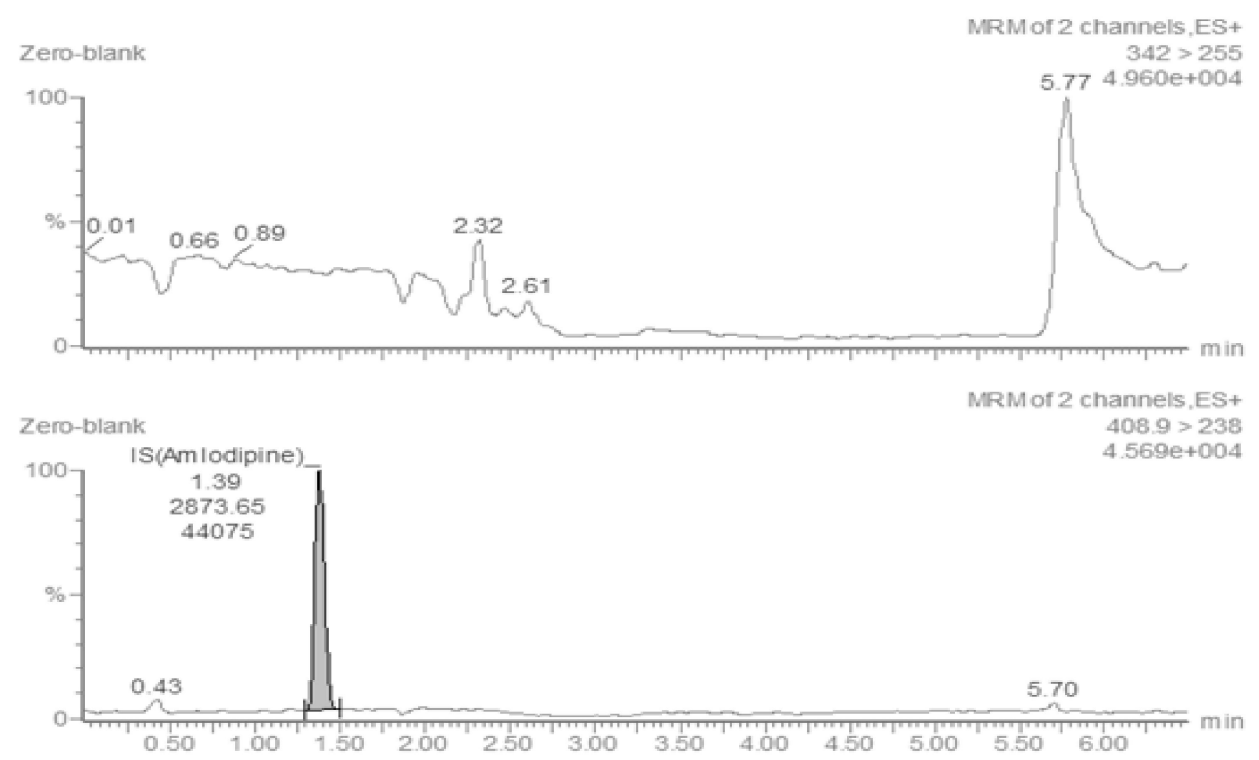

(B)

Figure 2. Cont. 

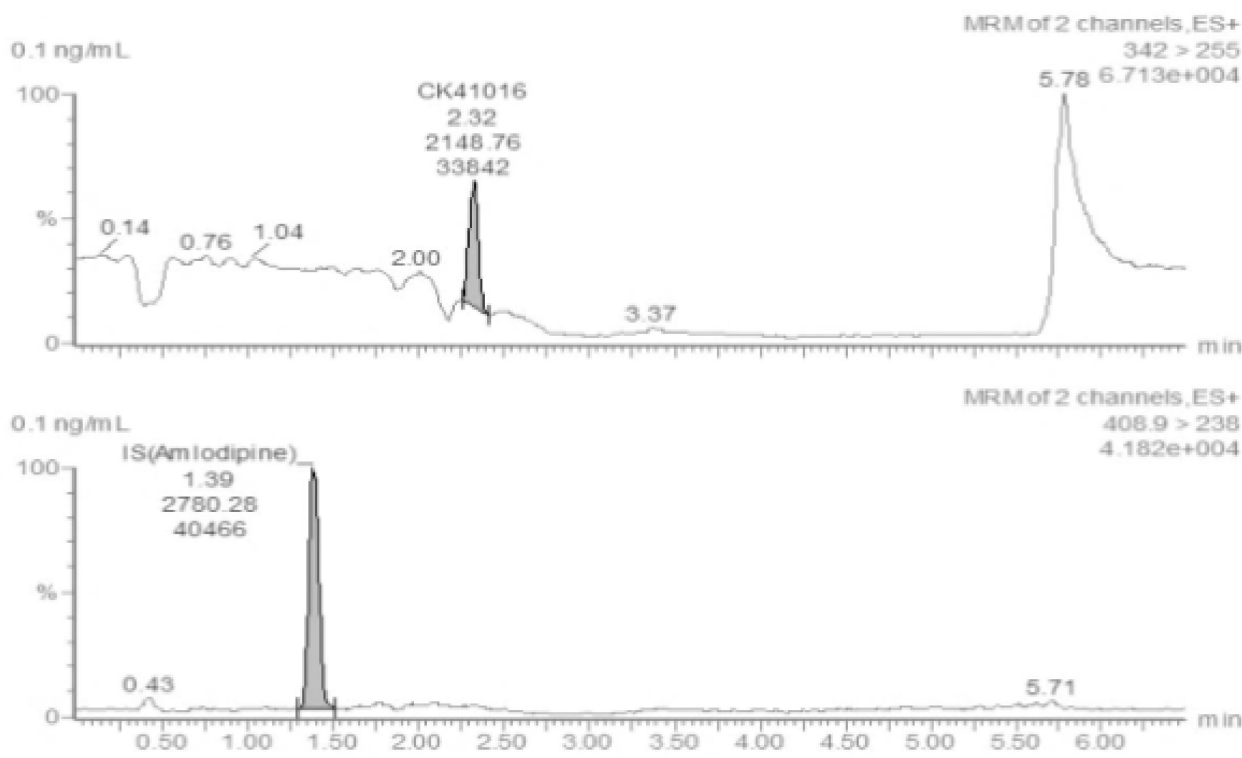

(C)

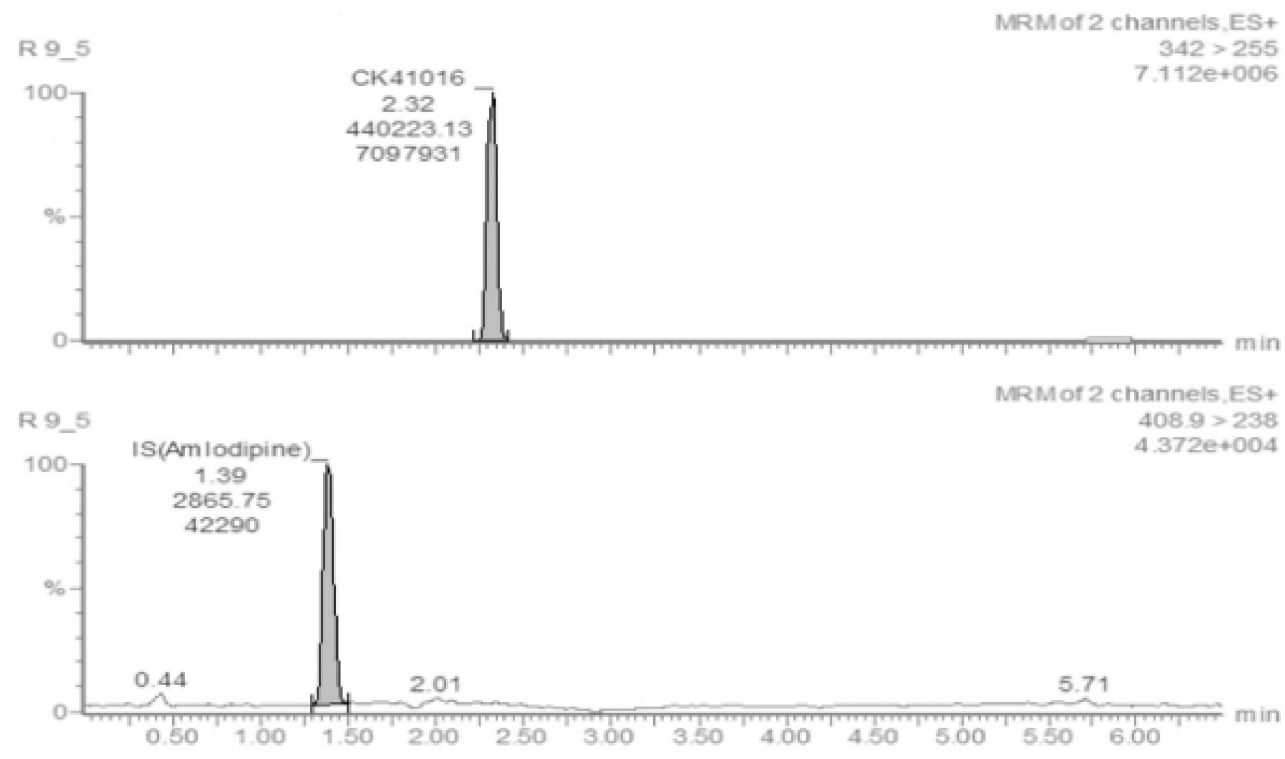

(D)

Figure 2. Representative multiple reaction monitoring (MRM) chromatograms of CK41016 in rat plasma. Blank rat plasma (A), zero-blank rat plasma spiked with IS (20 ng/mL) in extracted blank plasma (B), standard solution of CK41016 $(0.1 \mathrm{ng} / \mathrm{mL})$ and IS (C), and rat plasma taken at 5 min after eye drop administration of $75.21 \mu \mathrm{g} / \mathrm{kg}$ CK41016 (D).

\subsubsection{Calibration Curves and LLOQ}

The calibration curves of CK41016 showed a good linearity over the concentration range of 0.1-200 $\mathrm{ng} / \mathrm{mL}$ with a correlation coefficient for all standard curves exceeding 0.992 at each batch $(n=5)$. The linear regression equations of the calibration curves for CK41016 are represented in Table 1 , with $y$ as the analyte peak-area ratio to the IS and $x(\mathrm{ng} / \mathrm{mL})$ as the analyte concentrations in plasma (or organ tissue). The LLOQ of CK41016 was $0.1 \mathrm{ng} / \mathrm{mL}$. The UPLC-MS/MS analysis in this study provided 
a sufficient LLOQ for further PK study after the intravenous and eye drop administration of CK41016 in rats and rabbits.

Table 1. Calibration curves of CK41016 in plasma and tissues of rats and rabbits.

\begin{tabular}{cccc}
\hline & Matrix & Calibration Curve (Rat) & Calibration Curve (Rabbit) \\
\hline \multirow{6}{*}{ Eye ball } & Plasma & $\mathrm{y}=(0.21 \pm 0.01) \mathrm{x}+(0.01 \pm 0.01)$ & $\mathrm{y}=(1.00 \pm 0.06) \mathrm{x}+(0.22 \pm 0.06)$ \\
& Cornea & $\mathrm{y}=(0.31 \pm 0.01) \mathrm{x}+(0.14 \pm 0.004)$ & $\mathrm{y}=(0.98 \pm 0.12) \mathrm{x}+(0.12 \pm 0.05)$ \\
& Vitreous humor & $\mathrm{y}=(0.32 \pm 0.03) \mathrm{x}+(0.13 \pm 0.02)$ & $\mathrm{y}=(0.95 \pm 0.11) \mathrm{x}+(0.10 \pm 0.02)$ \\
& Retina \& choroid & $\mathrm{y}=(0.16 \pm 0.01) \mathrm{x}+(0.04 \pm 0.01)$ & $\mathrm{y}=(1.03 \pm 0.14) \mathrm{x}+(0.07 \pm 0.05)$ \\
& Aqueous humor ${ }^{\mathrm{a}}$ & - & $\mathrm{y}=(1.14 \pm 0.07) \mathrm{x}+(0.07 \pm 0.20)$ \\
& Heart & $\mathrm{y}=(0.17 \pm 0.01) \mathrm{x}+(0.01 \pm 0.01)$ & $\mathrm{y}=(0.80 \pm 0.09) \mathrm{x}+(0.08 \pm 0.08)$ \\
& Liver & $\mathrm{y}=(0.12 \pm 0.01) \mathrm{x}+(0.04 \pm 0.04)$ & $\mathrm{y}=(0.99 \pm 0.10) \mathrm{x}+(0.28 \pm 0.17)$ \\
& Brain & $\mathrm{y}=(0.12 \pm 0.004) \mathrm{x}-(0.01 \pm 0.04)$ & $\mathrm{y}=(0.98 \pm 0.10) \mathrm{x}+(0.05 \pm 0.05)$ \\
& Lung & $\mathrm{y}=(0.17 \pm 0.01) \mathrm{x}+(0.01 \pm 0.04)$ & $\mathrm{y}=(0.90 \pm 0.12) \mathrm{x}+(0.13 \pm 0.03)$ \\
& Kidney & $\mathrm{y}=(0.15 \pm 0.01) \mathrm{x}+(0.02 \pm 0.01)$ & $\mathrm{y}=(0.86 \pm 0.12) \mathrm{x}+(0.16 \pm 0.14)$ \\
GI tract & $\mathrm{b}$ & $\mathrm{y}=(0.13 \pm 0.01) \mathrm{x}+(0.01 \pm 0.04)$ & $\mathrm{y}=(0.96 \pm 0.11) \mathrm{x}+(0.12 \pm 0.12)$ \\
& Stomach & $\mathrm{y}=(0.69 \pm 0.06) \mathrm{x}+(0.06 \pm 0.10)$ \\
\hline
\end{tabular}

${ }^{a}$ The matrix of the rats did not include aqueous humor. ${ }^{b}$ GI tract of rabbits were classified into stomach and small intestine.

\subsubsection{Precision and Accuracy}

The intra-batch precision and accuracy at low, middle, and high quality control (QC) samples were in the ranges $2.52-5.02 \%$ and $95.33-103.93 \%$ (12.46\% and $100.33 \%$ for the LLOQ), respectively. The inter-batch precision and accuracy at low, middle, and high QC samples were in the ranges $2.94-4.45 \%$ and $96.44-100.40 \%$ (1.80\% and $102.11 \%$ for the LLOQ), respectively. These results indicate that all the values were within the acceptable range of $\pm 15 \%$ for QC samples and $\pm 20 \%$ for LLOQ, and this method showed satisfactory precision, accuracy, and reproducibility.

\subsubsection{Sensitivity}

The LLOQ for this quantitative method is set as $0.1 \mathrm{ng} / \mathrm{mL}$. The inter- and intra-batch results showed that LLOQ concentrations $(n=5)$ were within $100.33-102.11 \%$ of the theoretical value. Thus, it can be assured that the sensitivity for this quantitation method is appropriately set.

\subsubsection{Recovery and Matrix Effect}

The extraction recovery of CK41016 from rat plasma was $88.16 \% \pm 11.36 \%$, whereas the recovery of the IS was $92.48 \% \pm 6.50 \%$. The mean matrix effects for CK41016 at low and high concentrations were $0.99-1.00$, which indicated negligible suppression or enhancement.

\subsubsection{Stability}

The QC samples (low and high concentration) of CK41016 were stable at room temperature $\left(25^{\circ} \mathrm{C}\right)$ for $24 \mathrm{~h}$ without any significant degradation, and the relative errors (REs) were within 12.19\% for CK41016. Moreover, CK41016 was also considered stable after three freeze-thaw cycles in rat plasma (RE was less than $6.43 \%$ ). The stock solutions of CK41016 and the IS stored at $-20{ }^{\circ} \mathrm{C}$ in methanol were stable for a month, and the plasma samples stored at $-80{ }^{\circ} \mathrm{C}$ were stable for three months, with a variation of $<12.16 \%$. All the results showed that CK41016 was stable under the different storage conditions.

\subsubsection{Incurred Sample Reanalysis}

This assay was further evaluated using four rat samples in an incurred sample reanalysis (ISR). Two-third (67\%) of the repeated sample results should be within $20 \%$ for small molecules and $30 \%$ for large molecules. The results of all the reanalyzed samples were within $10 \%$ [26]. 
All results were within the criteria of the FDA guidance. Thus, the developed bioanalytical method for determining CK41016 was successfully validated.

\subsection{PK Study in Rats}

The validated method was applied to a PK study of CK41016 in rats after IV or eye drop administration. The plasma concentration-time curves of CK41016 after IV or eye drop administration are shown in Figure 3. The concentration-time profiles of CK41016 were adequately described by the two-compartment model without lag time using the WinNonlin ${ }^{\circledR}$ software (version 8.1, Certara ${ }^{\mathrm{TM}}$, Princeton, NJ, USA) program. The estimated results of PK parameters for CK41016 of each group are summarized in Table 2.

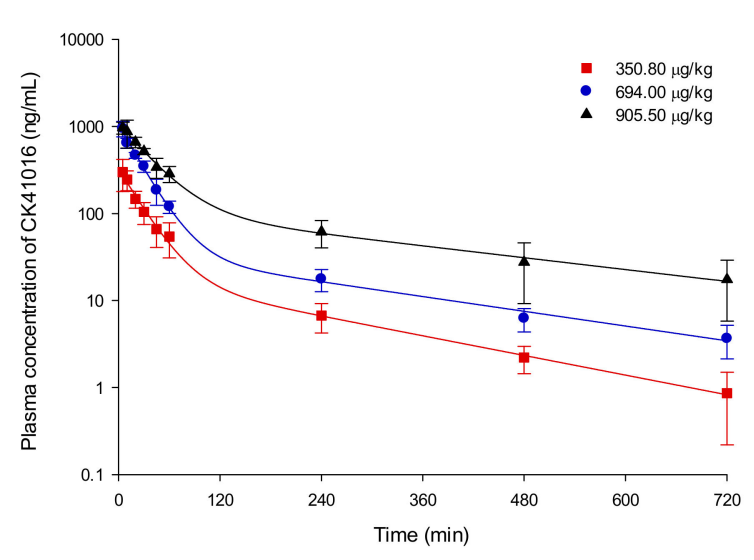

(A)

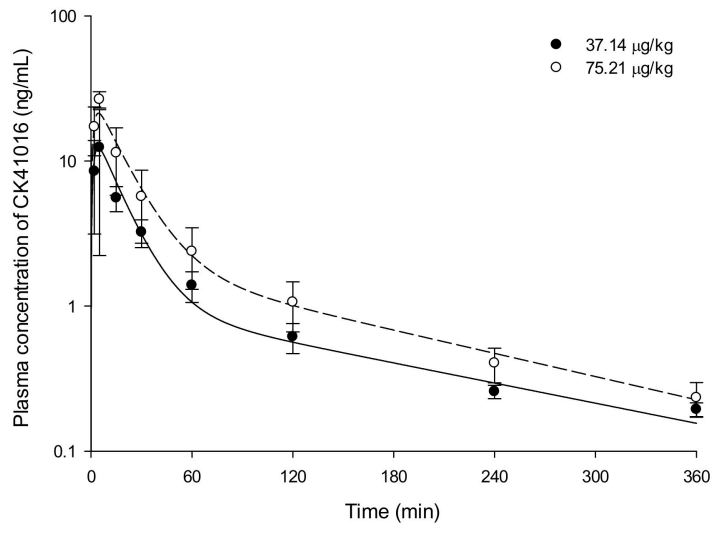

(B)

Figure 3. Plasma concentration-time profiles of CK41016 described by the two-compartment model after IV (A) or eye drop administration (B) in rats. Each value represents the mean \pm SD $(n=3-6)$.

Table 2. Pharmacokinetics (PK) parameters of CK41016 following IV or eye drop administration in rats (mean \pm SE, $n=3-6$ ).

\begin{tabular}{|c|c|c|c|c|c|}
\hline \multirow{2}{*}{ Parameter } & \multicolumn{3}{|c|}{ IV } & \multicolumn{2}{|l|}{ Eye Drop } \\
\hline & $350.80 \mu \mathrm{g} / \mathrm{kg}$ & $694.00 \mu \mathrm{g} / \mathrm{kg}$ & $905.50 \mu \mathrm{g} / \mathrm{kg}$ & $37.14 \mu \mathrm{g} / \mathrm{kg}$ & $75.21 \mu \mathrm{g} / \mathrm{kg}$ \\
\hline $\mathrm{CL}(\mathrm{mL} / \mathrm{min} / \mathrm{kg})^{\mathrm{a}, *}$ & $27.88 \pm 1.18$ & $19.28 \pm 0.75$ & $11.88 \pm 0.31$ & $88.69 \pm 3.36$ & $93.68 \pm 5.06$ \\
\hline $\mathrm{CL}_{\mathrm{D}}(\mathrm{mL} / \mathrm{min} / \mathrm{kg})^{a}$ & $10.03 \pm 1.35$ & $6.71 \pm 0.73$ & $9.54 \pm 0.81$ & $57.60 \pm 6.56$ & $46.48 \pm 2.92$ \\
\hline $\mathrm{V}(\mathrm{L} / \mathrm{kg})^{\mathrm{a}}$ & $1.07 \pm 0.10$ & $0.65 \pm 0.06$ & $0.82 \pm 0.05$ & $1.92 \pm 0.22$ & $1.58 \pm 0.75$ \\
\hline $\mathrm{V}_{2}(\mathrm{~L} / \mathrm{kg})^{\mathrm{a}}$ & $1.63 \pm 0.16$ & $1.48 \pm 0.16$ & $1.85 \pm 0.18$ & $7.20 \pm 1.28$ & $5.16 \pm 0.92$ \\
\hline$C_{\max }(\mu \mathrm{g} / \mathrm{mL})^{b}$ & $0.33 \pm 0.03 *$ & $1.06 \pm 0.09 *$ & $1.09 \pm 0.06$ & $0.01 \pm 0.004 *$ & $0.02 \pm 0.002 *$ \\
\hline $\mathrm{T}_{\max }(\min )$ & - & - & - & $4.30 \pm 1.50$ & $4.40 \pm 1.00$ \\
\hline $\mathrm{AUC}_{0-\infty}(\mu \mathrm{g} \cdot \mathrm{min} / \mathrm{mL}) *$ & $12.58 \pm 0.53$ & $35.99 \pm 1.40$ & $76.25 \pm 2.00$ & $0.42 \pm 0.05$ & $0.76 \pm 0.04$ \\
\hline $\mathrm{t}_{1 / 2}(\min )$ & $160.70 \pm 13.09$ & $213.18 \pm 21.62$ & $265.68 \pm 23.08$ & $129.28 \pm 32.11$ & $112.04 \pm 9.44$ \\
\hline $\mathrm{F}(\%)^{+}$ & - & - & - & 31.53 & 28.18 \\
\hline
\end{tabular}

a The value refers to the clearance $\left(\mathrm{CL} / \mathrm{F}\right.$ and $\left.\mathrm{CL}_{\mathrm{D}} / \mathrm{F}\right)$ and volume of distribution $\left(\mathrm{V} / \mathrm{F}\right.$ and $\left.\mathrm{V}_{2} / \mathrm{F}\right)$ after eye drop administration. ${ }^{b}$ The concentration is the $C_{0}(\mathrm{ng} / \mathrm{mL})$ after IV administration. ${ }^{*} p<0.05$ are significant differences according to dose within IV or eye drop administration groups. ${ }^{+}$Area under plasma concentration-time curve after IV administration $\left(\mathrm{AUC}_{\mathrm{IV}}\right)$ data of $350.80 \mu \mathrm{g} / \mathrm{kg}$ was used for the calculation of bioavailability $(\mathrm{F})(\%)$. AUC $0-\infty$, area under plasma concentration-time curve from time 0 to infinity.

Diagnostic plots for the final PK model of CK41016 after eye drop administration in rats, including the observed versus model-predicted concentration (A), individual weighted residual (IWRES) versus time (B), or model-predicted concentration (C) plots, are shown in Figure 4. 


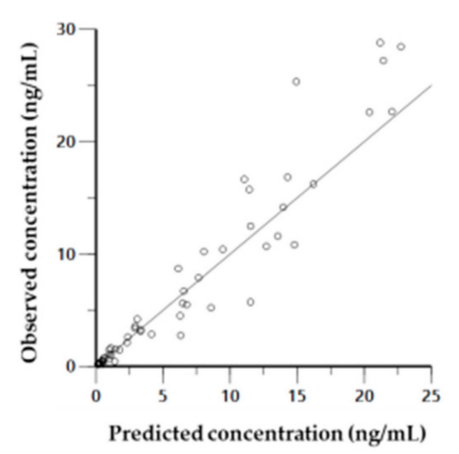

(A)

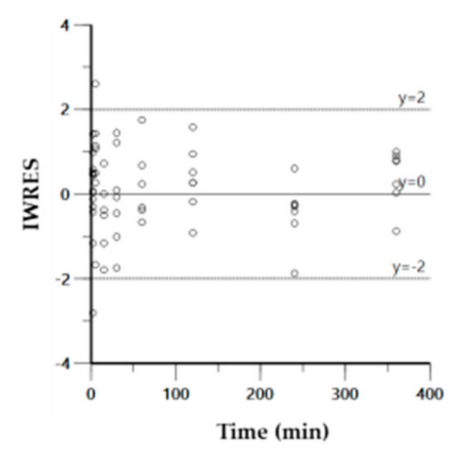

(B)

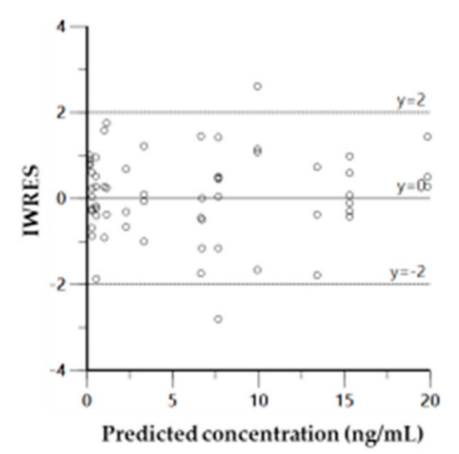

(C)

Figure 4. Diagnostic plots for the final pharmacokinetics (PK) model of CK41016 after eye drop administration in rats. Observed versus model-predicted concentration (A), individual weighted residual (IWRES) versus time (B), or model-predicted concentration (C).

As seen from Table 2, the mean elimination half-life $\left(t_{1 / 2}\right)$ was approximately 206.83 min after IV administration. The $\mathrm{AUC}_{0-\infty}$, area under plasma concentration-time curve from time 0 to infinity, significantly increased in a dose disproportional manner from $12.58 \mu \mathrm{g} \cdot \mathrm{min} / \mathrm{mL}$ for $350.80 \mu \mathrm{g} / \mathrm{kg}$ to $76.25 \mu \mathrm{g} \cdot \mathrm{min} / \mathrm{mL}$ for $905.50 \mu \mathrm{g} / \mathrm{kg}$. There was a significant $(p<0.05)$ difference in clearance (CL), which decreased nonlinearly from 27.88 to $11.88 \mathrm{~mL} / \mathrm{min} / \mathrm{kg}$ with the increasing dose. This result might be due to saturation of elimination by the enzyme-dependent clearance mechanism for the drug. After eye drop administration, the $\mathrm{T}_{\max }$ was $4.30-4.40 \mathrm{~min}$, suggesting that CK41016 was quickly absorbed into the body after administration of the eye drop.

Due to nonlinear PKs of CK41016 in rats, $\mathrm{AUC}_{\mathrm{IV}}$, area under plasma concentration-time curve after IV administration, data of $350.80 \mu \mathrm{g} / \mathrm{kg}$ was used for the calculation of bioavailability (F). The F value of the CK41016 eye drop in rats was $31.53 \%$ for $37.14 \mu \mathrm{g} / \mathrm{kg}$ and $28.18 \%$ for $75.21 \mu \mathrm{g} / \mathrm{kg}$.

The tissue distribution of CK41016 was evaluated at $720 \mathrm{~min}$ after IV administration and at two timepoints (60 and $360 \mathrm{~min}$ ) after eye drop administration in rats. The results are shown in Figure 5.

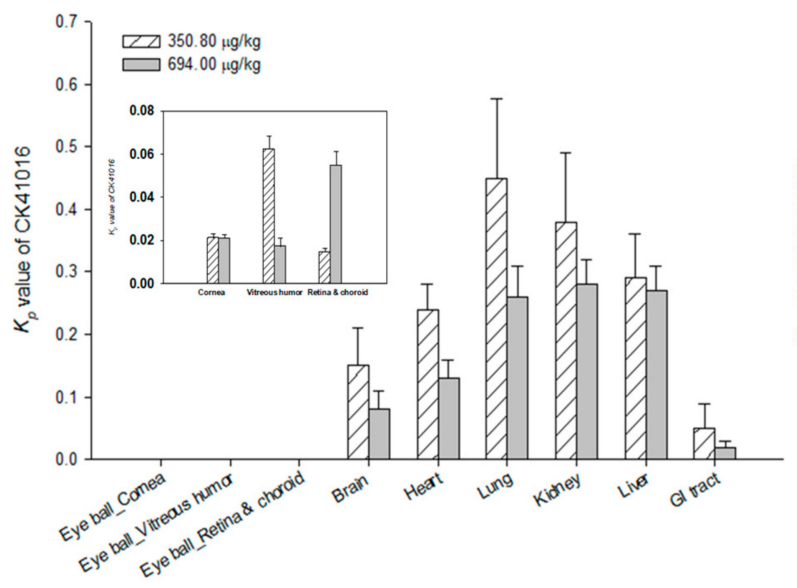

(A)

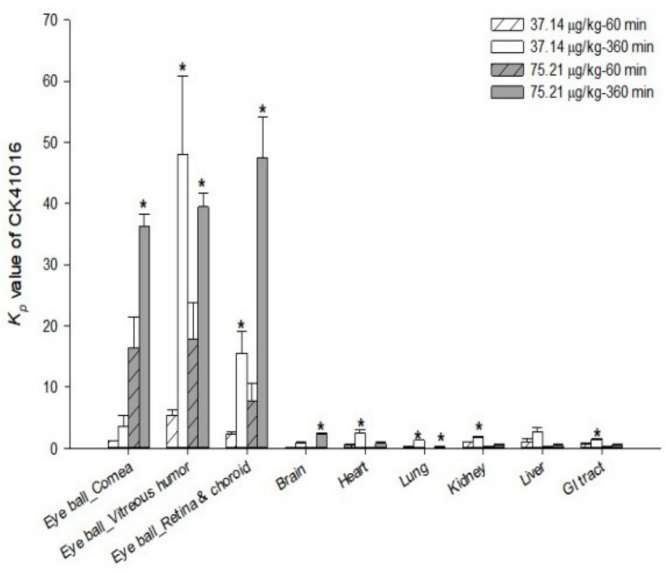

(B)

Figure 5. Mean tissue-to-plasma partition coefficient (Kp) values of CK41016 in rat tissues after IV (at $720 \mathrm{~min}$ ) (A) or eye drop (60 and $360 \mathrm{~min}$ ) administration (B) (mean $\pm \mathrm{SE}, n=5,{ }^{*} p<0.05$ between 60 and $360 \mathrm{~min})$. 
After eye drop administration in rats, CK41016 was rapidly distributed in tissues through systemic circulation. The tissue-to-plasma partition coefficient $(\mathrm{Kp})$ value of CK41016 in almost all rat tissues has increased over timepoints; however, it was markedly higher in the eyeballs than that in any other tissues. This is probably due to the fact that the instilled dose of CK41016 was in direct contact with the eyes. CK41016 was mainly distributed in the vitreous humor of the eyeballs. Significant differences in $\mathrm{Kp}$ values at two timepoints were observed in the eyeball tissues. Since AMD is a disease affecting the posterior segment of the eye, the treatment target areas of this disease are retina and choroid. Therefore, the drug for the treatment of AMD should be delivered to the back of the eye. The Kp values in vitreous humor, retina, and choroid were over 1, suggesting that CK41016 might have been delivered and well-distributed in the target areas up to $360 \mathrm{~min}$ after eye drop administration.

\subsection{PK Study in Rabbits}

To investigate species differences, a PK study of CK41016 was evaluated in rabbits after IV or eye drop administration. Plasma concentration-time curves of CK41016 after IV or eye drop administration are shown in Figure 6. Similar to the results in rats, concentration-time profiles of CK41016 were adequately described by the two-compartment model without lag time using the WinNonlin ${ }^{\circledR}$ software program. The estimated results of the PK parameters for CK41016 of each group are summarized in Table 3.

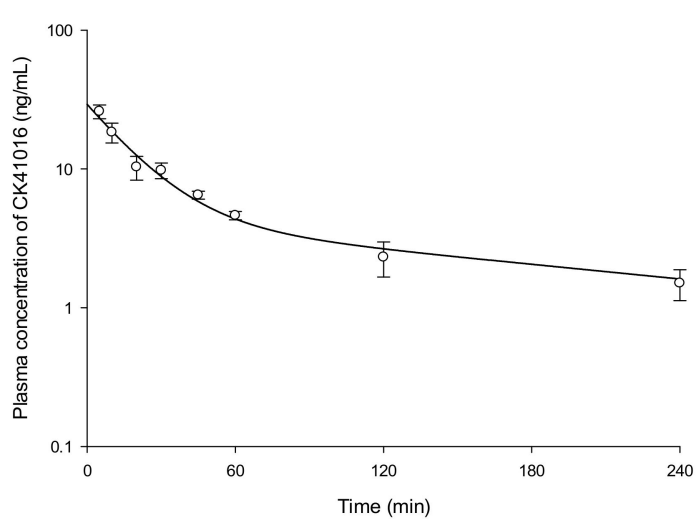

(A)

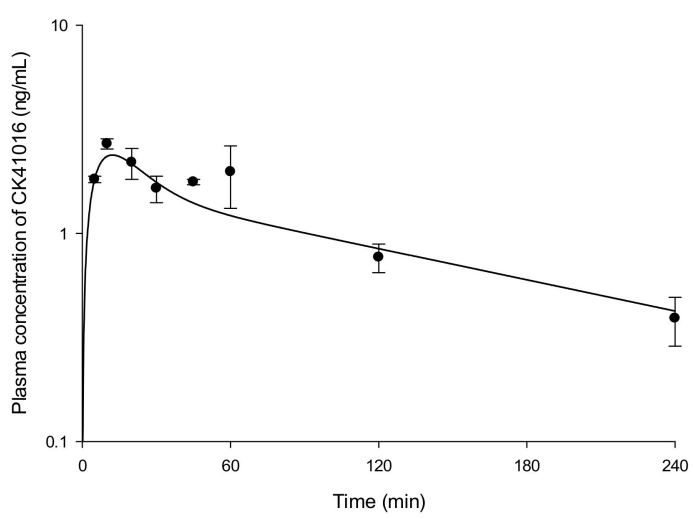

(B)

Figure 6. Plasma concentration-time profiles of CK41016 described by the two-compartment model after IV (A) or eye drop administration (B) in rabbits. Each value represents the mean \pm SD $(n=5)$.

Table 3. PK parameters of CK41016 following IV or eye drop administration in rabbits (Mean \pm SE, $n=5)$.

\begin{tabular}{ccc}
\hline \multirow{2}{*}{ Parameter } & IV & Eye Drop \\
\cline { 2 - 3 } & $\mathbf{6 6 . 0 0 ~} \mathbf{~ g} / \mathbf{k g}$ & $\mathbf{2 0 . 9 8} \boldsymbol{\mu g} / \mathbf{k g}$ \\
\hline $\mathrm{CL}(\mathrm{mL} / \mathrm{min} / \mathrm{kg})^{\mathrm{b}}$ & $43.90 \pm 6.36$ & $77.26 \pm 13.18$ \\
$\mathrm{CL}_{\mathrm{D}}(\mathrm{mL} / \mathrm{min} / \mathrm{kg})^{\mathrm{b}}$ & $51.70 \pm 9.54$ & $182.78 \pm 31.18$ \\
$\mathrm{~V}(\mathrm{~L} / \mathrm{kg})^{\mathrm{b}}$ & $2.35 \pm 0.29$ & $7.03 \pm 2.87$ \\
$\mathrm{~V}_{2}(\mathrm{~L} / \mathrm{kg})^{\mathrm{b}}$ & $5.74 \pm 0.38$ & $18.27 \pm 9.90$ \\
$\mathrm{C}_{\max }(\mathrm{ng} / \mathrm{mL})^{\mathrm{a}}$ & $28.14 \pm 3.47$ & $2.52 \pm 0.41$ \\
$\mathrm{~T}_{\max }(\mathrm{min})$ & - & $15.39 \pm 4.88$ \\
$\mathrm{AUC}_{0-\infty}(\mu \mathrm{g} \cdot \mathrm{min} / \mathrm{mL})$ & $1.50 \pm 0.22$ & $0.28 \pm 0.04$ \\
$\mathrm{t}_{1 / 2}(\mathrm{~min})$ & $104.38 \pm 57.41$ & $88.45 \pm 32.13$ \\
$\mathrm{~F}(\%)$ & - & 58.72 \\
\hline
\end{tabular}

a The concentration is the $\mathrm{C}_{0}(\mathrm{ng} / \mathrm{mL})$ after IV administration. ${ }^{\mathrm{b}}$ The value refers to the clearance $\left(\mathrm{CL} / \mathrm{F}\right.$ and $\left.C L_{\mathrm{D}} / \mathrm{F}\right)$ and volume of distribution ( $\mathrm{V} / \mathrm{F}$ and $\mathrm{V}_{2} / \mathrm{F}$ ) after eye drop administration. 
Diagnostic plots for the final PK model of CK41016 after eye drop administration in rabbits, including the observed versus model-predicted concentration $(\mathrm{A})$, individual weighted residual (IWRES) versus time (B) or model-predicted concentration (C) plots, are shown in Figure 7.

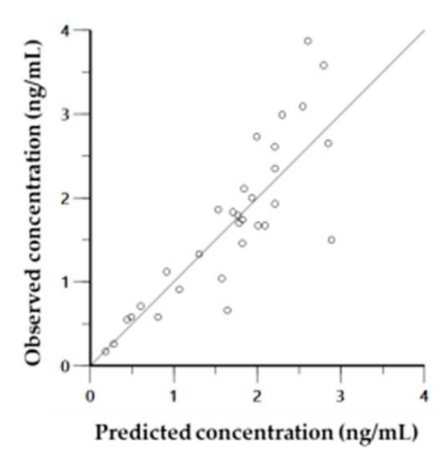

(A)

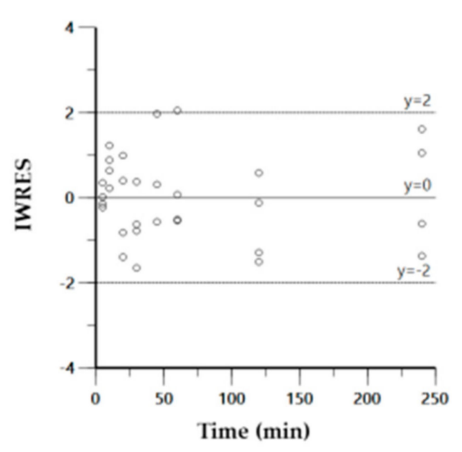

(B)

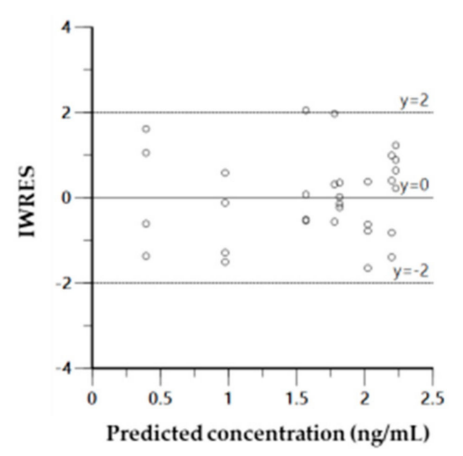

(C)

Figure 7. Diagnostic plots for the final PK model of CK41016 after eye drop administration in rabbits. Observed versus model-predicted concentration (A), individual weighted residual (IWRES) versus time (B), or model-predicted concentration (C).

As shown in Table 3, the mean elimination half-life was approximately 104.38 or $88.45 \mathrm{~min}$, and $\mathrm{T}_{\max }$ was 15.39 min after eye drop administration. The absolute eye drop F of CK41016 in rabbits was $58.72 \%$.

The tissue distribution of CK41016 was evaluated at $240 \mathrm{~min}$ after IV or eye drop administration in rabbits. Results are shown in Figure 8.

After eye drop administration in rabbits, CK41016 was distributed in major organs through systemic circulation, as well as the eyeball. Kp values of CK41016 in cornea, vitreous humor, retina, choroid, brain, lung, kidney, and small intestine were more than 1, indicating that CK41016 was well-distributed in these tissues at $240 \mathrm{~min}$ after eye drop administration. This suggests that CK41016 might have reached the posterior segment of the eyeball at $240 \mathrm{~min}$ after eye drop administration.

According to previous reports on the routes of drug delivery after eye drop administration [21,27], the ocular distribution of a drug is carried out via three major pathways after topical instillation: tear turnover, anterior (cornea/conjunctiva) region, and nasolacrimal drainage. Furthermore, there are four ways for a drug to reach the posterior of the eye. The drug will have to either (1) go through the cornea and aqueous chamber, penetrate the lens/iris to reach the vitreous before finally getting to the retina, (2) diffuse through the conjunctiva, sclera, and choroid to arrive at the retina, (3) go through horizontal diffusion from the cornea to the conjunctiva, or (4) go through the nasolacrimal drainage. The tissue distribution of CK41016 after eye drops in rats and rabbits shows that CK41016 was distributed to the cornea, vitreous humor, retina, and choroid but not to the aqueous humor. Based on the result, it can be hypothesized that the ocular penetration of CK41016 was carried out via a route similar to the pathway (2) from the report mentioned previously [27].

The $\mathrm{F}$ and tissue distribution in rabbits after eye drop administrations were different from those of rats. Although the highest distributed tissue was eyes in both rabbits and rats, the distribution trend within the eyeballs of rabbits was different from that of rats. After the eye drop administration in rats or rabbits, results showed that CK41016 reached the eyeballs in both species. However, less amounts of the drug were delivered to the retina of rabbits than in rats. This discrepancy might be due to the species differences. The corneal diameter and the anterior tissue volume of the rabbits are 2and 18-fold larger than that of the rats, respectively [28]. This could explain why more CK41016 was distributed in the cornea of the anterior segment but less in the posterior tissue in rabbits than in rats. 


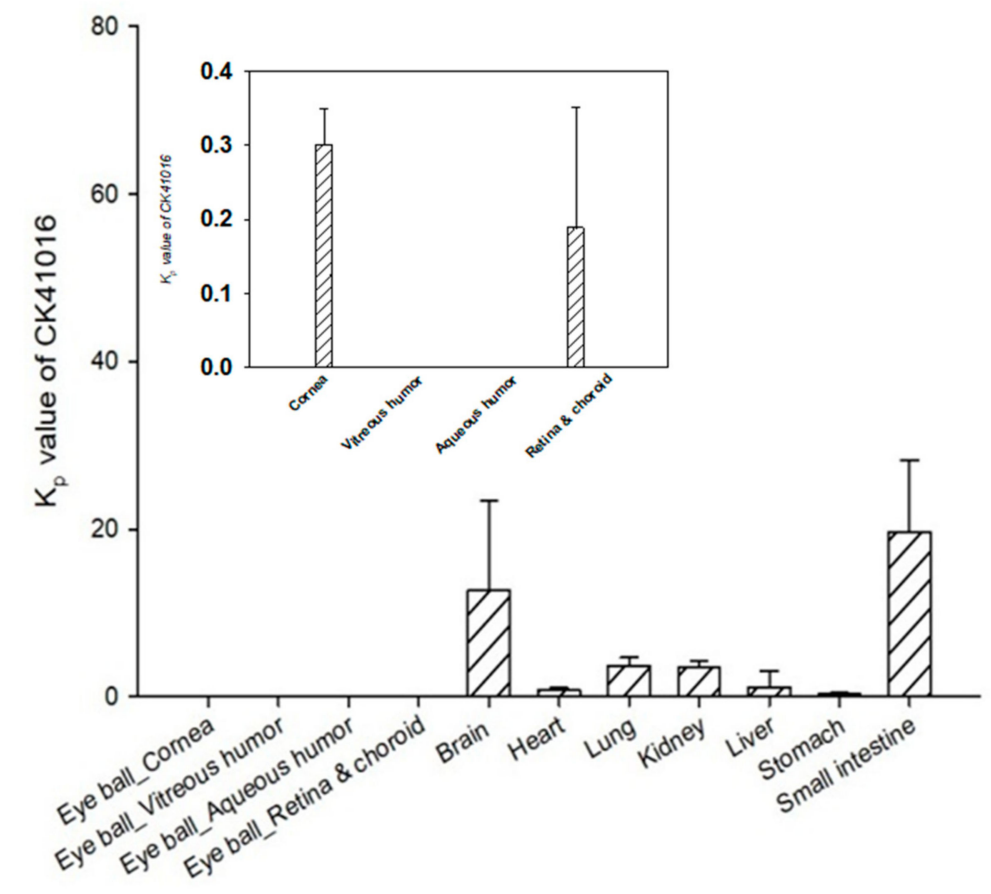

(A)

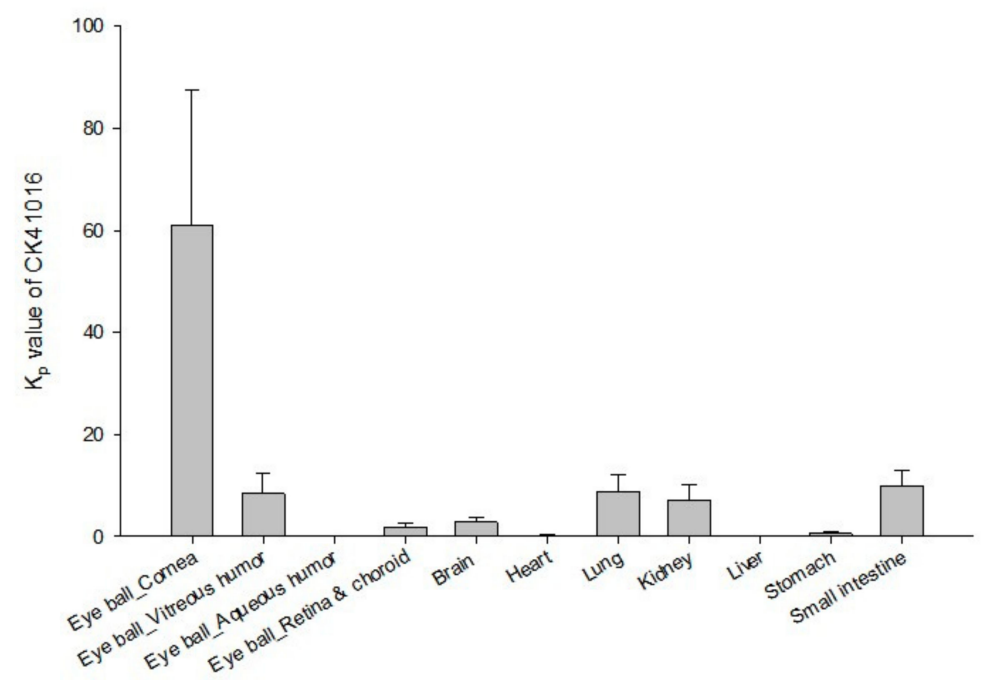

(B)

Figure 8. Mean Kp value of CK41016 in rabbit tissues at $240 \mathrm{~min}$ after IV (A) or eye drop administration (B) (mean $\pm \mathrm{SE}, n=5)$.

\subsection{Transport Assay of CK41016}

\subsubsection{Cytotoxicity Assay of CK41016}

Cytotoxicity of CK41016 at different concentrations to Caco-2 cells was evaluated using a CCK-8 kit. A CCK-8 assay is a sensitive colorimetric assay to determine the number of viable cells in cell 
proliferation and cytotoxicity assays. Figure 9 shows the cell viability of Caco- 2 cells after treatment with 0 (control), 0.5, 1, 5, 10, 50, and $100 \mu \mathrm{M}$ of CK41016 for $24 \mathrm{~h}$. Results of the CCK-8 assay showed that treatment with CK41016 at 0.5, 1, 5, 10, or $50 \mu \mathrm{M}$ had no cytotoxicity to Caco-2 cells. Based on these results, the treatment concentration of CK41016 for the bidirectional transport assay was chosen.

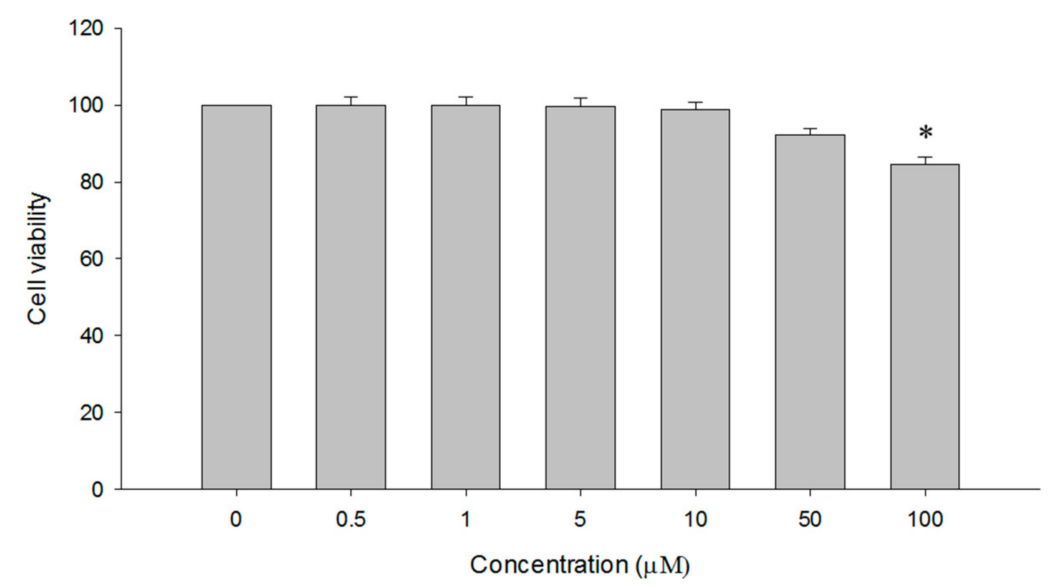

Figure 9. Cytotoxicity of CK41016 in Caco-2 cells ( $n=6$, mean \pm SD, $* p<0.05$ between control).

\subsubsection{Efflux Transport Assay of CK41016}

Based on the results of cytotoxicity assay, the bidirectional membrane transport of CK41016 at concentrations of 10, 20, 30, and $50 \mu \mathrm{M}$ in Caco-2 cell monolayers was evaluated. CK41016 was stable after $2 \mathrm{~h}$ of incubation in the transport medium at $37^{\circ} \mathrm{C}$. As shown in Table 4 , the permeability of CK4101 increased in a concentration-dependent manner. According to FDA guidance [29], any investigational drug with an efflux ratio (ER) greater than two is considered a potential substrate of active efflux transporters. ER of CK41016 was calculated to be 0.73 to 1.21 (Table 4), indicating that CK41016 was not a substrate of active efflux transporters. It also suggested that no significant efflux was involved in the membrane transport of CK41016. Permeability of CK41016 increased with concentration dependently. These results indicated that CK41016 permeated the membrane through passive diffusion.

Table 4. Permeability and efflux ratio of CK41016 in Caco-2 cell monolayers.

\begin{tabular}{cccc}
\hline \multirow{2}{*}{ CK41016 $(\mu \mathbf{M})$} & \multicolumn{2}{c}{ Caco-2 $\mathbf{P}_{\text {app }}\left(\times \mathbf{1 0}^{-\mathbf{6}} \mathbf{~} \mathbf{m} / \mathbf{s e c}\right)$} & \multirow{2}{*}{ Efflux Ratio } \\
\cline { 2 - 3 } & $\mathbf{A P} \rightarrow \mathbf{B L}$ & $\mathbf{B L} \rightarrow \mathbf{A P}$ & \\
\hline 10 & $11.52 \pm 0.55$ & $13.88 \pm 0.35$ & 1.21 \\
20 & $27.50 \pm 2.47$ & $27.59 \pm 0.66$ & 1.01 \\
30 & $32.96 \pm 1.47$ & $30.11 \pm 1.97$ & 0.92 \\
50 & $49.05 \pm 3.53$ & $35.98 \pm 2.55$ & 0.73 \\
\hline
\end{tabular}

There are many difficulties in delivering a drug to the posterior of the eye, since such delivery is limited by the blood-retina barrier, efflux transporter, and others $[21,25]$. The experimental results suggest that CK41016 was not a substrate of the efflux transporter, such as P-gp, and CK41016 was distributed in the retina (Figures 5B and 8B). CK 41016 not being the substrate of the efflux transporter could be one of the reasons why it was able to be delivered to the posterior segment of the eye, the therapeutic target for dry AMD. These results could support CK41016 eye drops as a potential dry AMD treatment. 


\section{Materials and Methods}

\subsection{Chemicals and Reagents}

Chemical structures of CK41016 (purity $>99.5 \%$ ) and amlodipine (purity $>99.9 \%$ ) as IS are shown in Figure 10. CK41016 was provided by the Kukje Pharmaceutical Co. (Gyeonggi-do, Korea), and the IS was purchased from Sigma-Aldrich (St. Louis, MO, USA). Methanol, acetonitrile, tetrahydrofuran, and methylene chloride were purchased from J.T. Baker (Phillipsburg, NJ, USA). Formic acid was purchased from Sigma-Aldrich (St. Louis, MO, USA). Distilled water (18.2 M $\Omega$ ) was obtained with an Elga Purelab Option-Q System (Elga Labwater, Marlow, UK). It was used throughout this study. All other chemicals were of HPLC or analytical grade.

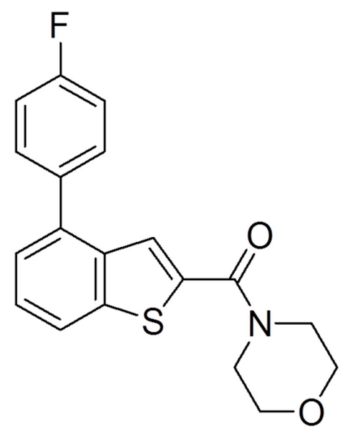

(A)<smiles>CCOC(=O)C1=C(COCCN)NC(C)=C(C(=O)OC)C1c1ccccc1Cl</smiles>

(B)

Figure 10. Chemical structures of CK41016 (A) and amlodipine (IS) (B).

\subsection{Quantification of CK41016 in Biological Samples}

The quantitation of CK41016 in biological samples (such as plasma and tissues of rats and rabbits and the transport medium) was performed with a newly developed bioanalytical method using an Acquity UPLC ${ }^{\circledR}$ System coupled with a mass spectrometer (Xevo TQ-S, Waters Corp., Milford, MA, USA). Chromatography was performed with a Kinetex biphenyl column $(2.1 \mathrm{~mm} \times 50 \mathrm{~mm}$, $1.7 \mu \mathrm{m}$ particle size, Phenomenex, Torrance, CA, USA) at a temperature of $25 \pm 5{ }^{\circ} \mathrm{C}$. The mobile phase consisted of $0.1 \%$ formic acid in water:tetrahydrofuran $(9: 1, v / v)$ and $0.1 \%$ formic acid in acetonitrile:tetrahydrofuran $(9: 1, v / v)$, with a gradient condition at a flow rate of $0.3 \mathrm{~mL} / \mathrm{min}$. The elution program was as follows: 0-0.5 $\mathrm{min}(25 \% \mathrm{~B}), 0.5-3.5 \mathrm{~min}(25-90 \% \mathrm{~B}), 3.5-5.0 \mathrm{~min}(90 \% \mathrm{~B}), 5.0-5.1 \mathrm{~min}$ (90-25\% B), and 5.1-6.5 $\mathrm{min}(25 \% \mathrm{~B})$. The mass spectrometer was operated in a multiple-reaction monitoring (MRM) mode with an electrospray ionization interface in the positive ion mode. Mass transitions were respectively $m / z 342.1 \rightarrow 255.1$ for CK41016 and $m / z 409.1 \rightarrow 238.2$ for the IS. Optimized parameters were accomplished as follows: capillary voltage, $3.3 \mathrm{kV}$; ion source temperature, $150{ }^{\circ} \mathrm{C}$; desolvation temperature, $350^{\circ} \mathrm{C}$; flow rate of cone gas, $150 \mathrm{~L} / \mathrm{h}$; flow rate of desolation gas, $600 \mathrm{~L} / \mathrm{h}$; and pressure of argon gas, $4.2 \times 10^{-3}$ mbar. The optimal collision energy was $20 \mathrm{eV}$ for CK41016 and $12 \mathrm{eV}$ for IS. The cone voltage was $38 \mathrm{~V}$ for CK41016 and $28 \mathrm{~V}$ for IS. Data acquisition and analysis were performed with Masslynx 4.1 software (Waters Corp., Milford, MA, USA).

CK41016 was extracted from plasma, tissues, and transport medium samples with a simple LLE method. Tissue samples were homogenized (Ultra-Turrax ${ }^{\circledR}$, IKA ${ }^{\circledR}$ T10 basic, Staufen, Germany) in five volumes of distilled water. To $50 \mu \mathrm{L}$ of each sample, $10 \mu \mathrm{L}$ of IS (amlodipine $20 \mathrm{ng} / \mathrm{mL}$ in $50 \%$ acetonitrile) was added using a repeating pipette. Then $900 \mu \mathrm{L}$ of methylene chloride was added and stirred for $3 \mathrm{~min}$ before centrifuging at 15,000× $g$ for $5 \mathrm{~min}$ at room temperature. After centrifugation, $800 \mu \mathrm{L}$ of the organic layer was transferred to a clean micro tube and evaporated at room temperature using a nitrogen evaporator. The residue was reconstituted in $100 \mu \mathrm{L}$ of $0.1 \%$ formic acid in $50 \%$ acetonitrile, stirred for $1 \mathrm{~min}$, and centrifuged at $15,000 \times g$ for $5 \mathrm{~min}$. Then $5 \mu \mathrm{L}$ of the supernatant was 
injected to a UPLC-MS/MS for analysis. The developed bioanalytical method was validated according to the FDA Guidance for Industry: Bioanalytical Method Validation [26].

\subsection{Animals and PK Study in Rats}

Normal male Sprague-Dawley rats (8-12 weeks, 250 270 g) were obtained from Orient Bio Inc. (Gyeonggi-do, Korea). All animals were separately kept in metabolic cages in an air-conditioned room with a controlled temperature of $23 \pm 2{ }^{\circ} \mathrm{C}$, a relative humidity of $50 \% \pm 10 \%$, and $12 \mathrm{~h}$ of a light/dark cycle. Rats were used for experiments after one week of acclimation. All animal experiments were approved by the Institutional Animal Care and Use Committee (IACUC, No. IACUC 180114) in CHA Laboratory Animal Research Center (Seongnam, South Korea).

According to administration doses or routes, male rats were randomly divided into five groups. In three groups, CK41016 was administered intravenously by a tail vein at $350.80,694.00$, or $905.50 \mu \mathrm{g} / \mathrm{kg}$ ( $n=3$ /group). The other two groups were instilled with one drop $(15 \mu \mathrm{L})$ of CK41016 eye drop into both eyes, which was equivalent to 37.14 or $75.21 \mu \mathrm{g} / \mathrm{kg}$ ( $n=6 /$ group). Blood samples were collected before administration and at predetermined times after administration (Table 5). Approximately $250 \mu \mathrm{L}$ of blood was collected via the jugular vein periodically into heparinized tubes. During our experiment, the rats were allowed to move freely in their metabolic cage, and blood samples were collected without rat fixation and anesthesia. Rats were also provided hydration via zonde to compensate for their blood loss. All collected blood was immediately centrifuged at $3000 \times g$ for $15 \mathrm{~min}$, and samples were stored at $-80{ }^{\circ} \mathrm{C}$ until analysis. At predetermined times after IV or eye drop administration, tissues were sampled after being sacrificed. Tissue samples of eyeballs (cornea, vitreous humor, retina, and choroid); liver; kidney; heart; lung; brain; and GI tract were collected, weighed, and stored at $-80{ }^{\circ} \mathrm{C}$ until analysis. PK parameters were calculated by compartmental analysis using a WinNonlin ${ }^{\circledR}$ software version 8.1 (Certara ${ }^{\mathrm{TM}}$, Princeton, NJ, USA). Differences of PK parameters between groups were tested by one-way analysis of variance (ANOVA). The Mann-Whitney U-test was used to evaluate the difference of the Kp value of each tissue at two time points. Statistical tests were performed with $\mathrm{R}$ software (R Core Team (2018), R: A language and environment for statistical computing. R Foundation for Statistical Computing, Vienna, Austria. (URL https://www.R-project.org/). Significant difference was considered at $p<0.05$.

Table 5. Experimental design of PK studies in rats.

\begin{tabular}{cccc}
\hline Group & Route & Dose $(\mu \mathrm{g} / \mathbf{k g})$ & Sampling Time $(\mathbf{m i n})$ \\
\hline 1 & & 350.80 & $5,10,20,30,45,60,240$ \\
2 & IV & 694.00 & $480,720^{\mathrm{a}}$ \\
3 & & 905.50 & $2,5,15,30,60^{*}, 120,240$ \\
4 & \multirow{2}{*}{ Eye drop } & 37.14 & $360^{\mathrm{b}}$ \\
\hline
\end{tabular}

a After IV administration, tissues were sampled at $720 \mathrm{~min}(350.80$ and $694.00 \mu \mathrm{g} / \mathrm{kg}) .{ }^{\mathrm{b}}$ After eye drop administration, tissues were sampled at 60 and $360 \mathrm{~min}$.

The absolute eye drop bioavailability (F) of CK41016 was calculated according to the following equation:

$$
\mathrm{F}(\%)=\left(\frac{A U C_{\text {eye drop }} / \text { Dose }_{\text {eye drop }}}{A U C_{I V} / \text { Dose }_{I V}}\right) \times 100
$$

where area under plasma concentration-time curve from time 0 to infinity $\left(\mathrm{AUC}_{\text {eye }}\right)$ drop and area under plasma concentration-time curve after IV administration $\left(A U C_{I V}\right)$ were the AUC values after eye drop and IV administration of CK41016, and Dose eye drop $_{\text {and Dose }}$ IV were actual doses via eye and IV administration, respectively. 


\subsection{Animals and PK Study in Rabbits}

Male New Zealand White rabbits were obtained from Koatech Inc. (Gyeonggi-do, Korea) to evaluate PKs in rabbits. They were kept in an air-conditioned room maintained with a $12 \mathrm{~h}$ light-dark cycle, a controlled ambient temperature $\left(23 \pm 2{ }^{\circ} \mathrm{C}\right)$, and a humidity of $50 \% \pm 10 \%$. This study was approved by the Institutional Animal Care and Use Committee (IACUC, No. IACUC 190032) of the CHA Laboratory Animal Research Center (Seongnam, South Korea).

Depending on administration route, CK41016 $(66.00 \mu \mathrm{g} / \mathrm{kg})$ was intravenously administered by ear vein or 1 drop $(50 \mu \mathrm{L})$ of CK41016 was instilled into each eye of the rabbits, which was equivalent to $20.98 \mu \mathrm{g} / \mathrm{kg}$ ( $n=5 /$ group). Blood samples were collected before administration and at 5, 10, 20, 30, $45,60,120$, and $240 \mathrm{~min}$ after the drug administration (Table 6). Approximately $1 \mathrm{~mL}$ of blood was collected via ear artery into heparinized tubes with an IV catheter (BD, Franklin Lakes, New Jersey, USA). Blood samples were immediately centrifuged at $3000 \times g$ for $15 \mathrm{~min}$ and then stored at $-80^{\circ} \mathrm{C}$ until analysis. After the last blood sample was obtained, rabbits administered with IV or eye drop were sacrificed, and tissues such as eyeballs, liver, kidney, heart, lung, brain, stomach, and small intestine were collected. Eyeballs were additionally separated into cornea, vitreous humor, aqueous humor, retina, and choroid. All tissue samples were stored at $-80{ }^{\circ} \mathrm{C}$ until analysis after obtaining their weights. The PK parameters of CK41016 were calculated by compartmental analysis using the WinNonlin ${ }^{\circledR}$ software version 8.1 (Certara ${ }^{\mathrm{TM}}$, Princeton, NJ, USA).

Table 6. Experimental design of PK studies in rabbits.

\begin{tabular}{cccc}
\hline Group & Route & Dose $(\mu \mathrm{g} / \mathbf{k g})$ & Sampling Time $(\mathbf{m i n})$ \\
\hline 1 & IV & 66.00 & $5,10,20,30,45,60,120$, \\
2 & Eye drop & 20.98 & 240 \\
\hline
\end{tabular}

\subsection{Efflux Transport Assay}

\subsubsection{Cell Culture}

Caco-2 cells were obtained from the American Type Culture Collection (Manassas, VA, USA) and grown in Dulbecco's modified Eagle medium (DMEM) supplemented with 10\% fetal bovine serum (Corning, NY, USA) and $1 \%$ penicillin streptomycin (Corning, NY, USA) in an atmosphere of $5 \% \mathrm{CO}_{2}$ at $37^{\circ} \mathrm{C}$ in a $\mathrm{CO}_{2}$ incubator (Heraeus BB15, Thermo Fisher Scientific Inc., MA, USA). The medium was changed every other day and harvested every 3-5 days with trypsin-EDTA. For transport study, Caco- 2 cells with passage number 51 were seeded into 12 -well Transwell plates $\left(1.12 \mathrm{~cm}^{2}\right.$ in surface, $0.4 \mu \mathrm{m}$ in pore size, $12 \mathrm{~mm}$ in diameter; Corning Costar Corporation, MA, USA) at a density of $1.9 \times 10^{7}$ cells/well. These cells were cultured for 21 days. The medium was replaced every other day. The integrity and transporter ability of cell monolayers were evaluated by measuring transepithelial electrical resistance (TEER) with an epithelial voltohmmeter (EVOM2, World Precision Instrument, Sarasota, FL, USA) before transport experiments. Caco-2 cell monolayers with TEER values exceeding $500 \Omega \mathrm{cm}^{2}$ were used in the transport study.

\subsubsection{In Vitro Cytotoxicity Assay}

Cytotoxicity of CK41016 to Caco-2 cells was evaluated using a Cell Counting Kit-8 (CCK-8) (Dojindo Molecular Technologies, Inc., Rockville, MD, USA). First, Caco-2 cells were seeded into 96-well plates at a density of $1.0 \times 10^{4}$ cells/well and preincubated at $37^{\circ} \mathrm{C}$ for $24 \mathrm{~h}$ with an atmosphere of $5 \% \mathrm{CO}_{2}$. Then, $10 \mu \mathrm{L}$ of $\mathrm{CK} 41016$ at various concentrations was added into each well, followed by incubation for $24 \mathrm{~h}$ in the incubator at same condition. A $10 \mu \mathrm{L}$ of CCK-8 reagent was added to each well of the 96-well plate. After incubation at $37^{\circ} \mathrm{C}$ with $5 \% \mathrm{CO}_{2}$ for $4 \mathrm{~h}$, absorbance of each well was measured at $450 \mathrm{~nm}$ using a 96-well plate reader (SpectraMax i3x, Molecular Devices, LLC, San Jose, CA, USA). Cell viability (\%) was calculated based on the measured value relative to the absorbance 
of cells exposed to the negative control. All data are shown as mean \pm standard deviation $(n=6)$. Statistical comparisons were made with Student's $t$-test. $P$-values of less than 0.05 were considered statistically significant.

\subsubsection{Transport Assay}

A bidirectional transport assay was conducted based on related previous reports and FDA guidance [27]. Before performing the transport assay, cells monolayers were washed twice using a

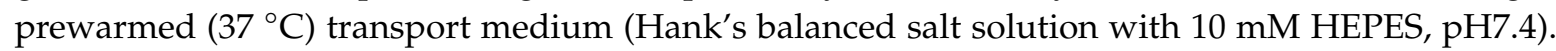
Cells were equilibrated at $37{ }^{\circ} \mathrm{C}$ in an atmosphere of $5 \% \mathrm{CO}_{2}$ for 30 min with the transport medium. Then, $10 \mathrm{mM}$ stock solution of CK41016 was prepared in DMSO and diluted with transport medium to $10,20,30$, and $50 \mu \mathrm{M}$.

The transport assay was conducted by adding each concentration of CK41016 to either the apical (AP, $0.5 \mathrm{~mL}$ ) or basolateral side $(\mathrm{BL}, 1.5 \mathrm{~mL})$. The receiver side was added the corresponding same volume of the transport medium. Plates were shaken gently for $2 \mathrm{~h}$ at $37{ }^{\circ} \mathrm{C}$ on a plate shaker. After $200 \mu \mathrm{L}$ samples were taken from the basolateral (for AP-BL transport) or apical (for BL-AP transport) chamber at 15, 30, 45, 60, 90, and $120 \mathrm{~min}$, the same volume of fresh transport medium was added as replacement. After taking the last samples, samples were also collected from the apical (for AP-BL transport) or basolateral (for BL-AP transport) chamber to analyze mass balance. Each sample was immediately frozen and stored at $-80^{\circ} \mathrm{C}$ until analysis with established UPLC-MS/MS method. The apparent permeability coefficients $\left(\mathrm{P}_{\mathrm{app}}\right)$ were calculated as shown below:

$$
\mathrm{P}_{\mathrm{app}}=(\mathrm{dQ} / \mathrm{dt}) /\left(\mathrm{A} \times \mathrm{C}_{0}\right)
$$

where $\mathrm{dQ} / \mathrm{dt}(\mu \mathrm{mol} / \mathrm{s})$ was the cumulative rate transported of $\mathrm{CK} 41016$ on the receiver side, $\mathrm{A}\left(\mathrm{cm}^{2}\right)$ was the membrane surface area, and $C_{0}(\mu \mathrm{M})$ was the initial concentration in the donor compartment.

The efflux ratio was calculated with the following equation:

$$
\text { Efflux ratio }=P_{a p p}(B L \rightarrow A P) / P_{a p p}(A P \rightarrow B L)
$$

where $\mathrm{P}_{\mathrm{app}}(\mathrm{BL} \rightarrow \mathrm{AP})$ was the $\mathrm{P}_{\mathrm{app}}$ of the basolateral side to the apical side, and $\mathrm{P}_{\mathrm{app}}(\mathrm{AP} \rightarrow \mathrm{BL})$ was the $\mathrm{P}_{\mathrm{app}}$ of the apical side to the basolateral side.

\section{Conclusions}

In this study, a selective, sensitive, and reliable UPLC-MS/MS method was developed and validated for the quantification of CK41016. The PK model and tissue distribution of CK41016 were successfully evaluated after IV or eye drop administrations to rats and rabbits. The efflux transport mechanism of CK41016 was also investigated using a Caco-2 cell monolayer model. The discrepancy in PK parameters and tissue distribution trends between rats and rabbits might be due to species differences, and these features should be considered in clinical trials. In addition, metabolic mechanisms of CK41016 that might be associated with the nonlinear PK of the drug should be further investigated via metabolic assays. Additionally, the causes for differences in PKs and tissue distribution among species need to be investigated to predict PKs of CK41016 in humans in the future. Overall, the results of this study suggest that CK41016 eye drops might be a potential new drug candidate for dry AMD treatment.

Author Contributions: Conceptualization, H.-Y.C.; data curation, E.-J.C.; formal analysis, E.-J.C., G.-W.C., and H.-W.J.; funding acquisition, Y.G.K.; investigation, E.-J.C.; methodology, E.-J.C.; resources, J.-H.L. and H.J.B.; software, G.-W.C.; supervision, H.-Y.C.; validation, E.-J.C. and G.-W.C.; writing-original draft, E.-J.C. and J.H.K.; and writing-review and editing, Y.-B.L. and H.-Y.C. The final manuscript was read and approved by all authors. All authors have read and agreed to the published version of the manuscript.

Funding: This research received no external funding.

Acknowledgments: This research was supported by the Kukje Pharmaceutical Co., Korea. 
Conflicts of Interest: The authors declare no conflict of interest.

\section{References}

1. Brazier, Y. What is age-related macular degeneration (AMD)? In Medical News Today. 2018. Available online: https://www.medicalnewstoday.com/articles/152105.php (accessed on 7 October 2019).

2. Heier, J.S.; Brown, D.M.; Chong, V.; Korobelnik, J.F.; Kaiser, P.K.; Nguyen, Q.D.; Kirchhof, B.; Ho, A.; Ogura, Y.; Yancopoulos, G.D.; et al. Intravitreal aflibercept (VEGF trap-eye) in wet age-related macular degeneration. Ophthalmology 2012, 119, 2537-2548. [CrossRef] [PubMed]

3. Velez-Montoya, R.; Oliver, S.C.; Olson, J.L.; Fine, S.L.; Mandava, N.; Quiroz-Mercado, H. Current knowledge and trends in age-related macular degeneration: today's and future treatments. Retina 2013, 33, 1487-1502. [CrossRef]

4. Bowes Rickman, C.; Farsiu, S.; Toth, C.A.; Klingeborn, M. Dry age-related macular degeneration: Mechanisms, therapeutic targets, and imaging. Invest. Ophthalmol. Vis. Sci. 2013, 54, ORSF68-ORSF80. [CrossRef]

5. Ivandic, B.T.; Ivandic, T. Low-level laser therapy improves vision in patients with age-related macular degeneration. Photomed. Laser Surg. 2008, 26, 241-245. [CrossRef] [PubMed]

6. Prahs, P.; Walter, A.; Regler, R.; Theisen-Kunde, D.; Birngruber, R.; Brinkmann, R.; Framme, C. Selective retina therapy (SRT) in patients with geographic atrophy due to age-related macular degeneration. Graefes. Arch. Clin. Exp. Ophthalmol. 2010, 248, 651-658. [CrossRef] [PubMed]

7. Virgili, G.; Michelessi, M.; Parodi, M.B.; Bacherini, D.; Evans, J.R. Laser treatment of drusen to prevent progression to advanced age-related macular degeneration. Cochrane Database Syst. Rev. 2015, CD006537. [CrossRef] [PubMed]

8. Boyer, D.; Freund, K.B.; Regillo, C.; Levy, M.H.; Garg, S. Long-term (60-month) results for the implantable miniature telescope: Efficacy and safety outcomes stratified by age in patients with end-stage age-related macular degeneration. Clin. Ophthalmol. 2015, 9, 1099-1107. [CrossRef] [PubMed]

9. Qureshi, M.A.; Robbie, S.J.; Tabernero, J.; Artal, P. Injectable intraocular telescope: Pilot study. J. Cataract Refract. Surg. 2015, 41, 2125-2135. [CrossRef]

10. Koss, M.J.; Kurz, P.; Tsobanelis, T.; Lehmacher, W.; Fassbender, C.; Klingel, R.; Koch, F.H. Prospective, randomized, controlled clinical study evaluating the efficacy of Rheopheresis for dry age-related macular degeneration. Dry AMD treatment with Rheopheresis Trial-ART. Graefes Arch. Clin. Exp. Ophthalmol. 2009, 247, 1297-1306. [CrossRef]

11. Rencova, E.; Blaha, M.; Studnicka, J.; Blaha, V.; Lanska, M.; Renc, O.; Stepanov, A.; Kratochvilova, V.; Langrova, H. Preservation of the Photoreceptor Inner/Outer Segment Junction in Dry Age-Related Macular Degeneration Treated by Rheohemapheresis. J. Ophthalmol. 2015, 2015, 359747. [CrossRef]

12. Carr, A.J.; Smart, M.J.; Ramsden, C.M.; Powner, M.B.; da Cruz, L.; Coffey, P.J. Development of human embryonic stem cell therapies for age-related macular degeneration. Trends Neurosci. 2013, 36, 385-395. [CrossRef] [PubMed]

13. Schwartz, S.D.; Tan, G.; Hosseini, H.; Nagiel, A. Subretinal Transplantation of Embryonic Stem Cell-Derived Retinal Pigment Epithelium for the Treatment of Macular Degeneration: An Assessment at 4 Years. Invest. Ophthalmol. Vis. Sci. 2016, 57, ORSFc1-ORSFc9. [CrossRef] [PubMed]

14. Kassa, E.; Ciulla, T.A.; Hussain, R.M.; Dugel, P.U. Complement inhibition as a therapeutic strategy in retinal disorders. Expert Opin. Biol. Ther. 2019, 19, 335-342. [CrossRef] [PubMed]

15. Wong, W.T.; Kam, W.; Cunningham, D.; Harrington, M.; Hammel, K.; Meyerle, C.B.; Cukras, C.; Chew, E.Y.; Sadda, S.R.; Ferris, F.L. Treatment of geographic atrophy by the topical administration of OT-551: Results of a phase II clinical trial. Invest. Ophthalmol. Vis. Sc.i 2010, 51, 6131-6139. [CrossRef] [PubMed]

16. Holz, F.G.; Sadda, S.R.; Busbee, B.; Chew, E.Y.; Mitchell, P.; Tufail, A.; Brittain, C.; Ferrara, D.; Gray, S.; Honigberg, L.; et al. Chroma; Spectri Study, I. Efficacy and Safety of Lampalizumab for Geographic Atrophy Due to Age-Related Macular Degeneration: Chroma and Spectri Phase 3 Randomized Clinical Trials. JAMA Ophthalmol. 2018, 136, 666-677. [CrossRef] [PubMed]

17. Bandello, F.; Sacconi, R.; Querques, L.; Corbelli, E.; Cicinelli, M.V.; Querques, G. Recent advances in the management of dry age-related macular degeneration: A review. F1000Res. 2017, 6, 245. [CrossRef]

18. Taskintuna, I.; Elsayed, M.E.; Schatz, P. Update on Clinical Trials in Dry Age-related Macular Degeneration. Middle East Afr. J. Ophthalmol. 2016, 23, 13-26. 
19. Tanito, M.; Li, F.; Anderson, R.E. Protection of retinal pigment epithelium by OT-551 and its metabolite TEMPOL-H against light-induced damage in rats. Exp. Eye. Res. 2010, 91, 111-114. [CrossRef]

20. Jang, K.H.; Do, Y.J.; Koo, T.S.; Choi, J.S.; Song, E.J.; Hwang, Y.; Bae, H.J.; Lee, J.H.; Kim, E. Protective effect of RIPK1-inhibitory compound in in vivo models for retinal degenerative disease. Exp. Eye Res. 2019, 180, 8-17. [CrossRef]

21. Boddu, S.H.; Gupta, H.; Patel, S. Drug delivery to the back of the eye following topical administration: An update on research and patenting activity. Recent Pat. Drug Deliv. Formul. 2014, 8, 27-36. [CrossRef]

22. International Transporter, C.; Giacomini, K.M.; Huang, S.M.; Tweedie, D.J.; Benet, L.Z.; Brouwer, K.L.; Chu, X.; Dahlin, A.; Evers, R.; Fischer, V.; et al. Membrane transporters in drug development. Nat. Rev. Drug Discov. 2010, 9, 215-236. [CrossRef] [PubMed]

23. Kennedy, B.G.; Mangini, N.J. P-glycoprotein expression in human retinal pigment epithelium. Mol. Vis. 2002, 8, 422-430. [PubMed]

24. Constable, P.A.; Lawrenson, J.G.; Dolman, D.E.; Arden, G.B.; Abbott, N.J. P-Glycoprotein expression in human retinal pigment epithelium cell lines. Exp. Eye Res. 2006, 83, 24-30. [CrossRef] [PubMed]

25. Mitra, A.K. Role of transporters in ocular drug delivery system. Pharm. Res. 2009, 26, 1192-1196. [CrossRef]

26. FDA. The Guidance for Industry: Bioanalytical Method Validation; U.S. Department of Health and Human Services, F. a. D. A., Center for Drug Evaluation and Research (CDER): Rockville, MD, USA, 2018.

27. Tsai, C.H.; Wang, P.Y.; Lin, I.C.; Huang, H.; Liu, G.S.; Tseng, C.L. Ocular Drug Delivery: Role of Degradable Polymeric Nanocarriers for Ophthalmic Application. Int. J. Mol. Sci. 2018, 19, 2830. [CrossRef]

28. Thomasy, S.M.; Eaton, J.S.; Timberlake, M.J.; Miller, P.E.; Matsumoto, S.; Murphy, C.J. Species Differences in the Geometry of the Anterior Segment Differentially Affect Anterior Chamber Cell Scoring Systems in Laboratory Animals. J. Ocul. Pharmacol. Ther. 2016, 32, 28-37. [CrossRef]

29. FDA. Guidance for Industry: In Vitro Metabolismand TransporterMediated Drug-Drug Interaction Studies; U.S. Department of Health and Human Services, F. a. D. A., Center for Drug Evaluation and Research (CDER): Rockville, MD, USA, 2017.

Sample Availability: Samples of the compounds are available from the authors.

(C) 2020 by the authors. Licensee MDPI, Basel, Switzerland. This article is an open access article distributed under the terms and conditions of the Creative Commons Attribution (CC BY) license (http://creativecommons.org/licenses/by/4.0/). 